\title{
ORBITAL METASTASES. A REPORT OF FOUR CASES AND A REVIEW OF THE LITERATURE
}

\author{
METÁSTASIS ORBITARIAS. SERIE DE CUATRO CASOS \\ Y REVISIÓN DE LA LITERATURA
}

\author{
GONZÁLEZ F ${ }^{1}$, LÓPEZ-COUTO C ${ }^{2}$
}

\begin{abstract}
Objective: To report four cases of orbital metastases and review the literature related to this condition.

Methods: We reviewed the clinical records of the four patients and the appropriate world literature.

Results: Two women 51 and 82 years old presented with orbital metastases from a primary breast tumour and a third woman (45 years old) had orbital metastases from a primary lung tumour. One man 60 years old presented with a metastases from a renal tumour. Two patients, one with breast metastases and the one with lung metastases, died of their disease. The remaining two patients are still alive with stable disease at the time of writing this report.

Conclusion: The metastases in our series originated from tumours that frequently produce orbital metastases- the breast, lung and kidney. The clinical characteristics of the orbital syndromes they caused were similar to those reported in the literature. The clinical presentation was torpid in three cases and had a fulminating course in the
\end{abstract}

\begin{abstract}
RESUMEN
Objetivo: Describir cuatro casos clínicos de metástasis orbitarias y hacer una revisión de la literatura sobre esta patología.

Métodos: Revisión de historias clínicas y de la bibliografía.

Resultados: Dos mujeres de 51 y 82 años de edad presentaron una metástasis orbitaria procedente de un tumor de mama y una tercera (45 años de edad) de una neoplasia pulmonar. Un paciente varón de 60 años de edad presentó una metástasis orbitaria procedente de un tumor renal. Dos de los pacientes, una paciente con metástasis de tumor de mama y la paciente con metástasis de tumor pulmonar, fallecieron a consecuencia de su tumor primario, la primera a los dos años y medio y la segunda dos meses después de los primeros signos de metástasis orbitaria. Los otros dos pacientes continúan vivos en situación estable.

Conclusiones: Las metástasis en nuestra serie se originaron en tumores de mama, pulmón y riñón, que se encuentran entre los tumores que con más frecuencia producen metástasis orbitarias. Las características clínicas del síndrome orbitario coin-
\end{abstract}

\footnotetext{
Received: 23/1/06. Accepted: 26/7/06.

Ophthalmology Service of the Santiago de Compostela University Hospital, Spain. Physiology Dept. and Telefónica Telemedicine Chair of the

Medicine College of Santiago de Compostela University, Spain.

$1 \mathrm{Ph} . \mathrm{D}$. in Medicine and surgery.

2 Graduate in Medicine and surgery.

This paper has been prepared with the subsidy BFU2004-01839 of the Education Ministry and FEDER.
}

Correspondence:

Francisco González

Departamento de Fisiología

Facultad de Medicina

Universidad de Santiago de Compostela

C/. San Francisco, s/n

E-15782 Santiago de Compostela

Spain

E-mail: francisco.gonzalez@usc.es 
case with lung metastases (Arch Soc Esp Oftalmol 2006; 81: 451-462).

Keywords: Metastases, orbit, breast, lung, kidney. cidieron con los datos publicados en la literatura revisada. La forma de presentación del cuadro fue tórpida en tres casos y fulminante en el caso de la metástasis pulmonar. El diagnostico de metástasis orbitaria es importante porque puede ser el primer signo de un tumor distante y puede permitir realizar tratamientos precoces que mejoren la calidad de vida de los pacientes.

Palabras clave: Metástasis, órbita, mama, pulmón, riñón.

\section{INTRODUCTION}

Although most tumors affecting the orbit are primary or reach the orbit by means of adjacency, a number of those are the product of metastasis in a primary tumor located at a distance (1) and maybe the first sign of a neoplasic process. Even though prognosis is generally pessimistic, early diagnosis may facilitate some kind of therapy with beneficial palliative effects, inducing remission of the primary tumor or, in some instances, full recovery.

The fact that $50 \%$ of cases with orbit metastases visit their ophthalmologist without even knowing about the existence of a primary tumor (2) emphasizes the role played by this specialist in the diagnosis of this pathology. Adult males and children frequently are not aware of the existence of a primary tumor (3-8) when orbit metastasis appears. On the other hand, women have usually already been diagnosed with mammary carcinoma (2). We describe a series of four cases of orbit metastasis.

\section{SUBJECTS, MATERIAL AND METHODOLOGY}

We describe herein the cases of four patients diagnosed with orbit metastasis at our medical center Ophthalmology Department from 2002 to 2005, although one of those cases was first observed in 2001 due to orbit-related issues. We list the most representative clinical findings in relation with orbit metastases. The series consists of three women and one man whose primary tumor was located in the mammary gland in two of the cases, another in the lungs and one in the kidney.

\section{FINDINGS}

CASE 1. 82-year-old woman who attends our ophthalmology service in April 2001 complaining of difficulties to look to the right and reporting diplopia. During exploration, we detect alterations in extraocular motility for the right eye (RE) without accurately determining which muscles were affected and palpebral ptosis. Computerized Axial Tomography (CAT) of orbit shows a mass at the level of the internal wall on the right orbit following the line of the internal rectum muscle and apparently adhered to the eye globe (fig. 1). The most likely diagnosis is an orbital sarcoma and a more complete examination is prescribed, but the patient does not come back until March 2002. At this point, through ophthalmological exploration of the RE we observe no mobility in the ocular globe, slight exophthalmos, loss of vision (no perception of light) and minor ingurgitation of scleral vessels (fig. 2). During a general examination, we find an injury on the right mammary gland compatible with a neoplasic process (fig. 2). We perform a fine needle aspiration puncture (FNAP) and the diagnosis was infiltrant ductal carcinoma. Hormonal therapy was prescribed and the patient remains stable five years after first attending our ophthalmological services.

CASE 2. 67-year-old woman with a history of infiltrant ductal carcinoma on the right mammary gland 16 years ago. In January 2001, due to a fracture on the left hip, a gammagraphic study was undertaken which revealed multiple focal points for bone uptake, subsequently diagnosing Stage IV mammary neoplasia. In February 2001 we observe a slight exophthalmos on the left eye (LE), afferent pupillary defect, limited eye movements, visual 

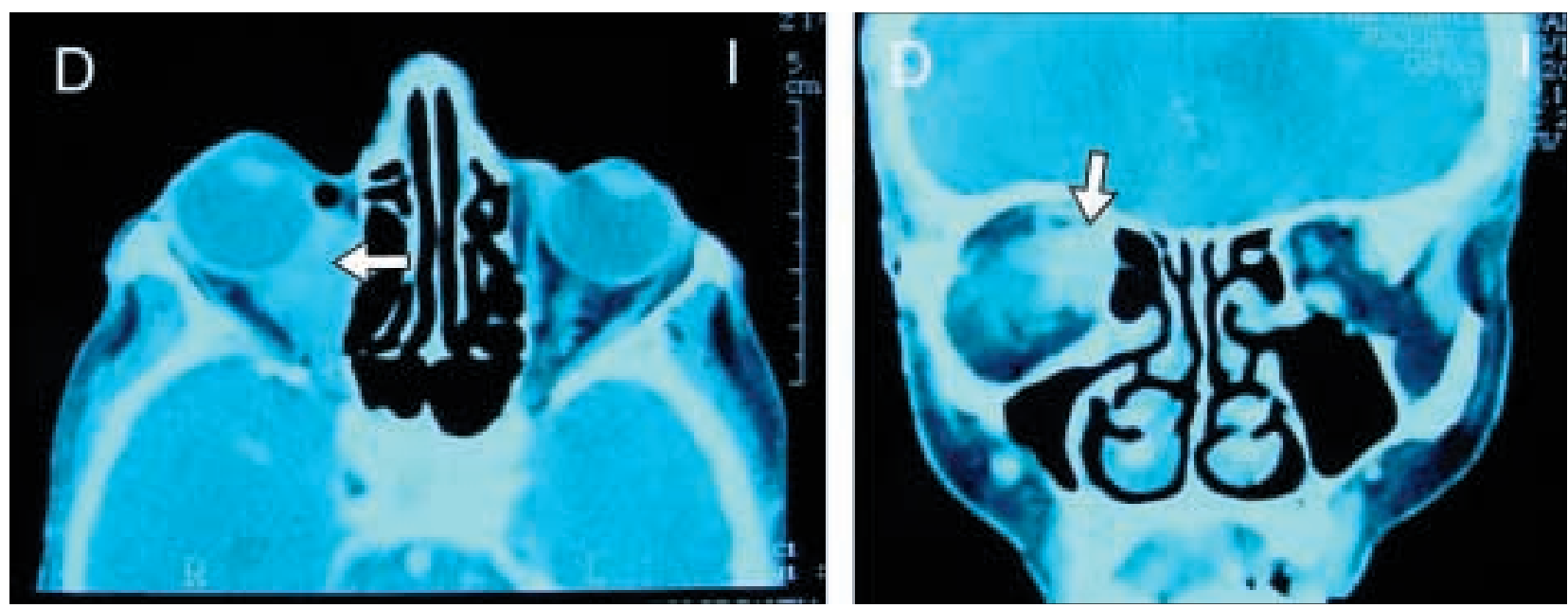

Fig. 1: Case 1. Axial and coronal CAT reveals a mass in the medial area of the right orbit (arrows).
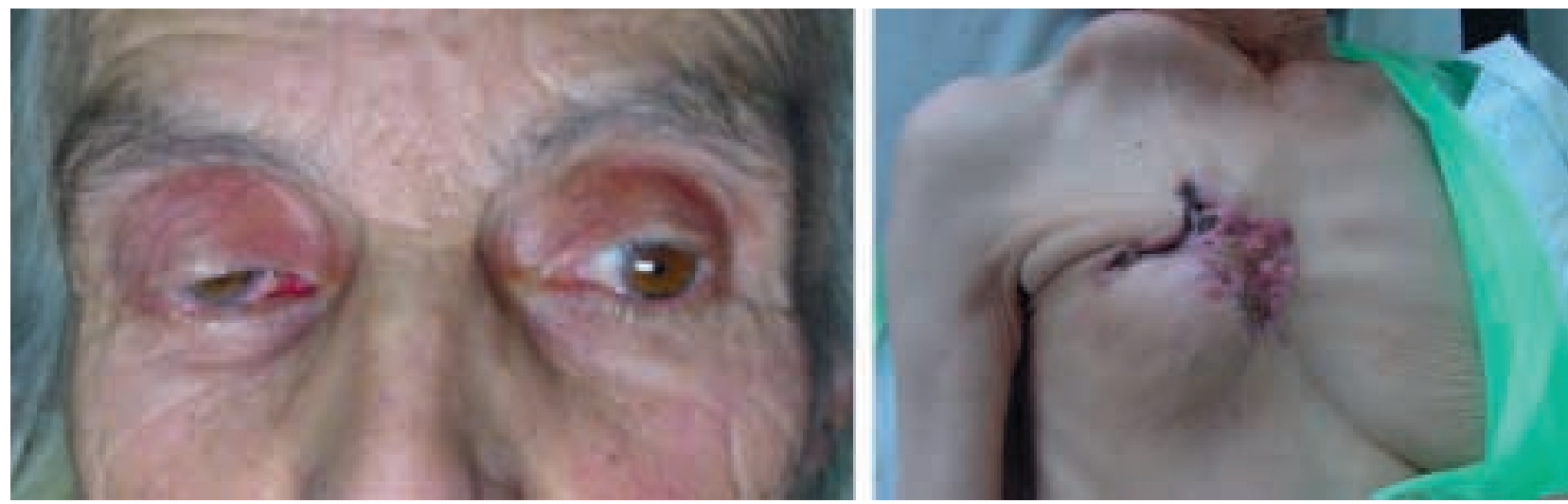

Fig. 2: Case 1. Left: The right eye almost did not move. Right: Lesion on the right mammary gland found during clinical examination.

acuity of light perception, intense papilledema and elevation of the retina on the upper half.

In March 2001 the patient underwent treatment with palliative radiotherapy in the area of the hip fracture and hormonal treatment, with positive evolution. In January 2003, a Nuclear Magnetic Resonance (NMR) revealed the existence of vertebral metastases with D8 compression and associated fracture. During ophthalmological exploration performed at the same time, patient shows a chart similar to the one reported two years earlier, with palpebral ptosis, ingurgitation of episcleral veins and conjunctival chemosis (fig. 3). The CAT and NMR performed showed a mass almost covering the whole left orbit and compressing the eye globe (figs. 4 and 5). A FNAP was performed on the orbital mass, yielding positive for adenocarcinoma, so that diag- nosis was metastasis of the mammary primary tumor. Six months later, the patient exhibited sepsis secondary to a urinary tract infection and glucose decompensation, and died.

CASE 3. 45-year-old female who was taken to the emergency ward in February 2004 complaining of pain and OI proptosis, visual acuity of 0.5 and papilledema. The NMR performed revealed a possible pseudotumor with great thickening of the medium rectum. Treatment with systemic chortichoids was prescribed, improving initially her condition, which subsequently deteriorated. Upon her arrival, her visual acuity allowed her to count fingers; thanks to an IOP, VA improved to 0.3 ; papilledema, conjunctival chemosis, exophthalmos, semi-mydriasis, complete limitation of ocular movements and slight palpebral ptosis (fig. 6). 

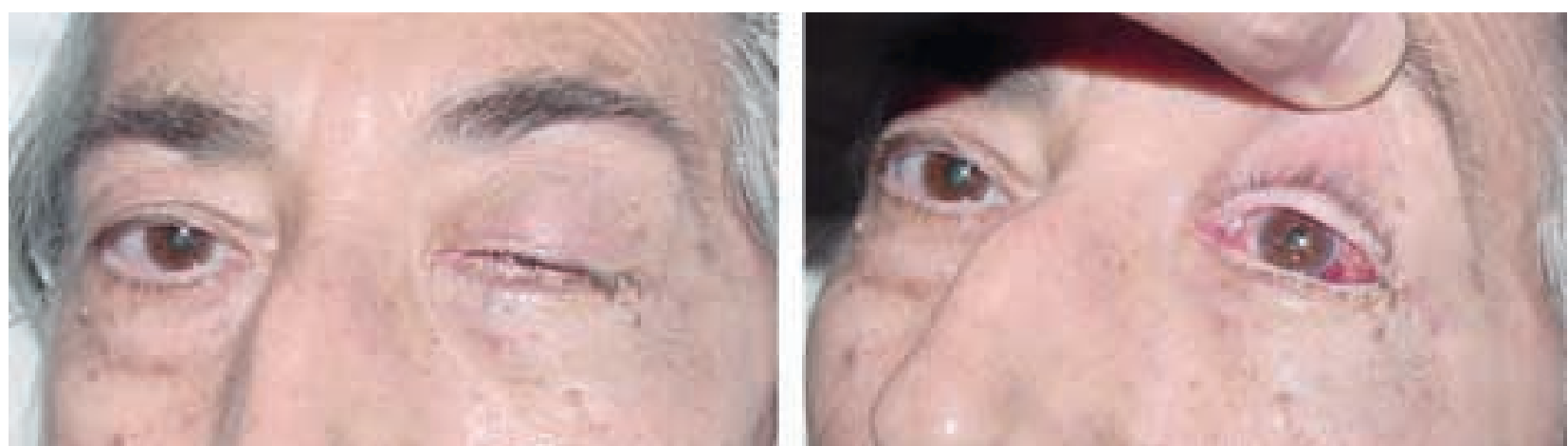

Fig. 3: Case 2. Left: Photograph shows LE ptosis. Right: When raising the eyelid, episcleral venous ingurgitation can be seen.
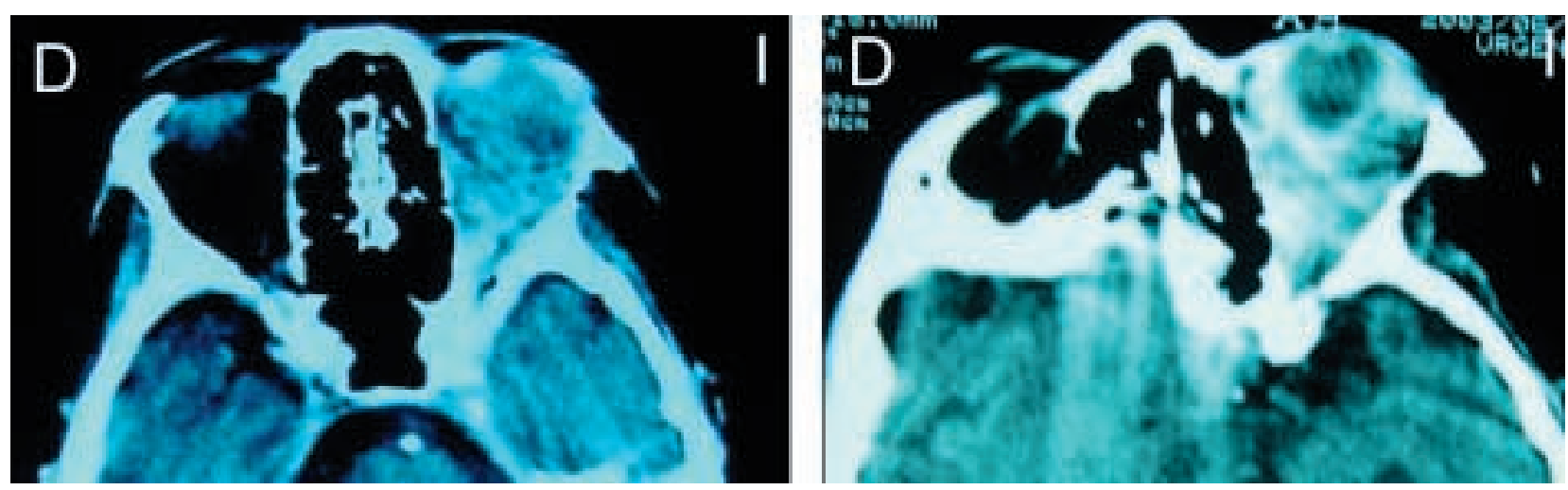

Fig. 4: Case 2. Orbital CAT. Left: a mass covering most of the orbit is observed. Right: The same study performed 4 months later revealed a similar aspect.
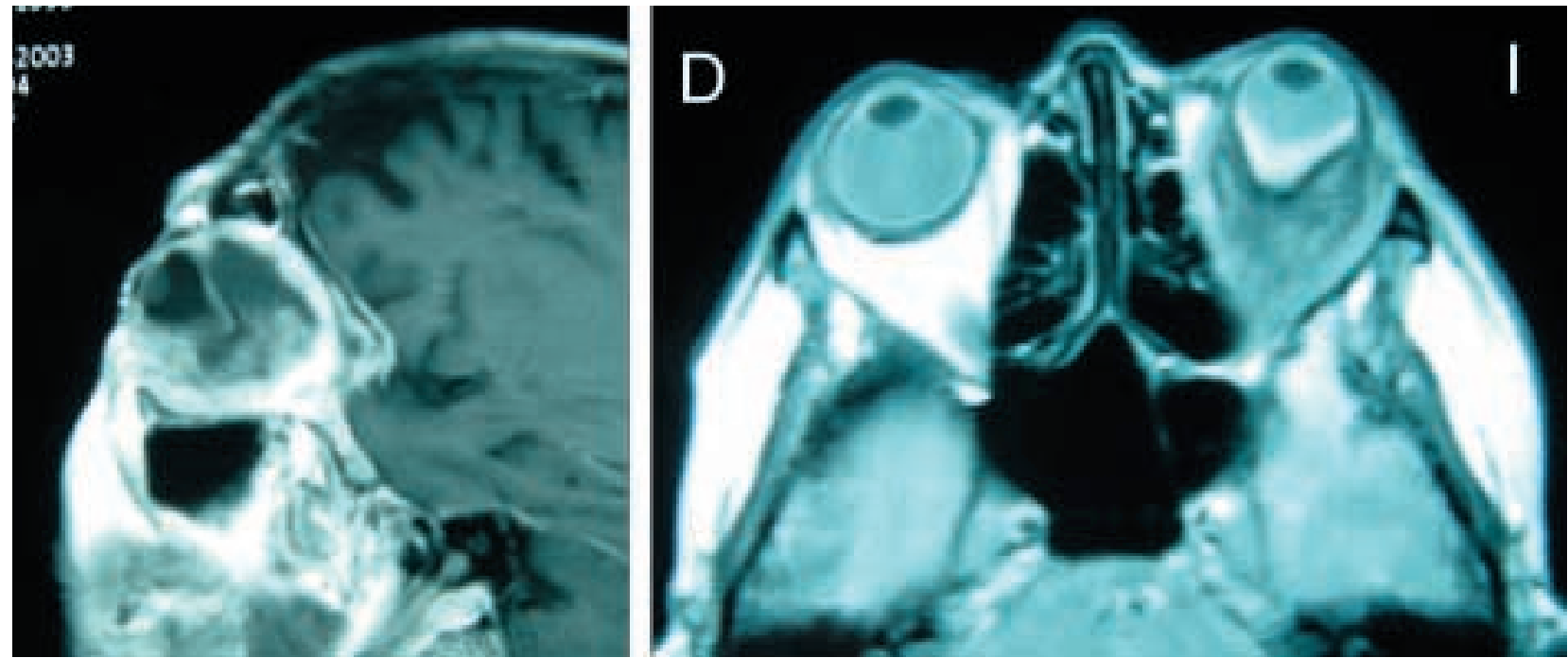

Fig. 5: Case 2. Left: NMR sagittal cut including the left orbit. Right: NMR horizontal cut. The invasion of the left orbit can be clearly seen. 

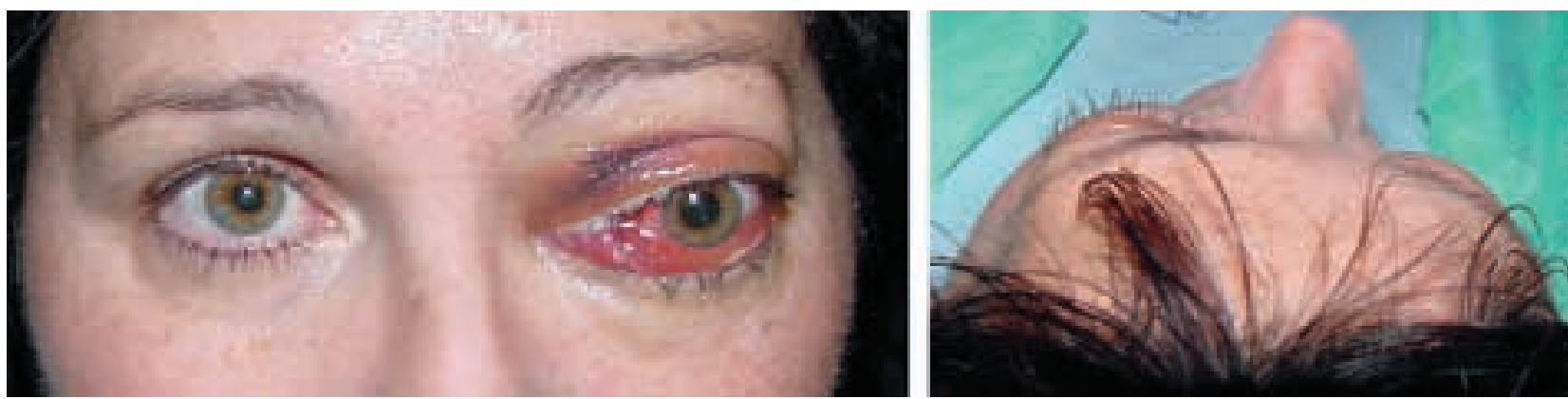

Fig. 6: Case 3. Left: frontal photograph of patient showing exophthalmos on the LE, exotropia, semi-mydriasis and conjunctival chemosis. Right: Photograph of the same patient taken from above in order to show protrusion of the left eye.
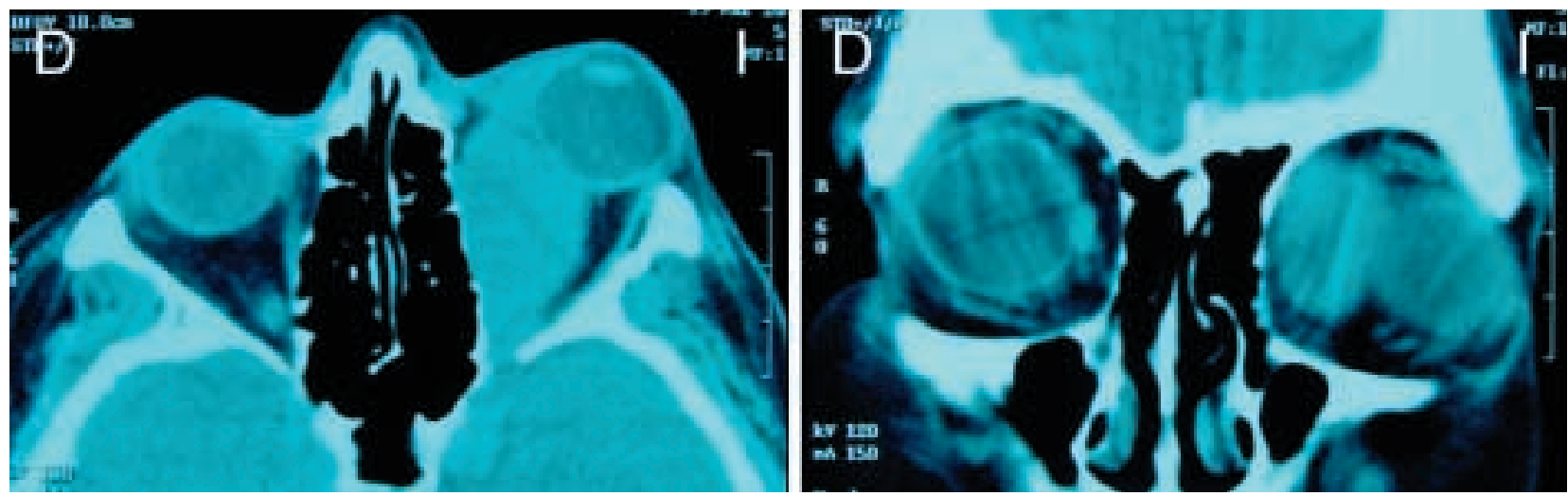

Fig. 7: Case 3. Horizontal (left) and coronal (right) NMR sections revealing a mass in the medial area of the left orbit compressing and displacing the ocular globe.

An orbital CAT revealed a mass invading the medial area of the left orbit, including the internal rectum and up to the ocular globe, deforming it (fig. 7). We performed a FNAP and the sample obtained suggested the existence of an epidermoid neoplasia; subsequently, we began a systemic exploration in order to discard the presence of a primary tumor. A simple thorax x-ray reveals atelectasia on the lower left lobe (fig. 8) and via a bronchoscopy we found an endobronchial mass. We obtained a biopsy and the resulting diagnosis was an epidermoid bronchogenic carcinoma, confirming that this is the originating tumor for the orbital metastasis. A thorax CAT performed later on confirmed the existence of a mass in the lower left lobe. The patient's condition deteriorated in April 2004 and died as a result of her lung tumor.

CASE 4. 60-year-old male patient with a history of perforating traumatism on the LE with a plant thorn which led to loss of vision on that eye and exotropia.

At the age of 35 he underwent surgery to correct the exotropia. In June 2002, he attended the doc-

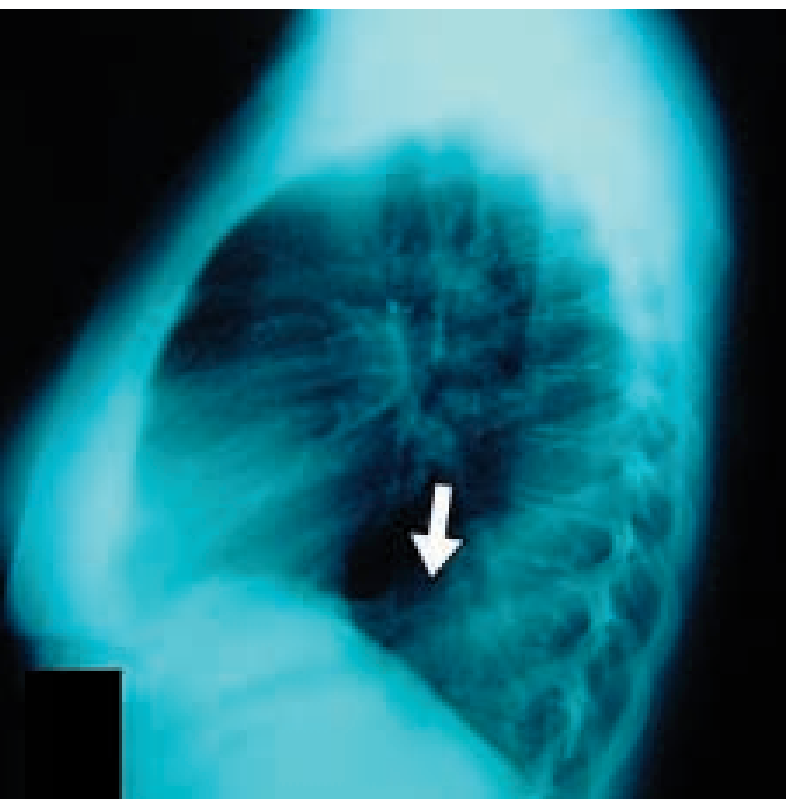

Fig. 8: Case 3. Simple lateral thorax $x$-ray revealing signs of atelectasia on the lower left lobe (arrow). 


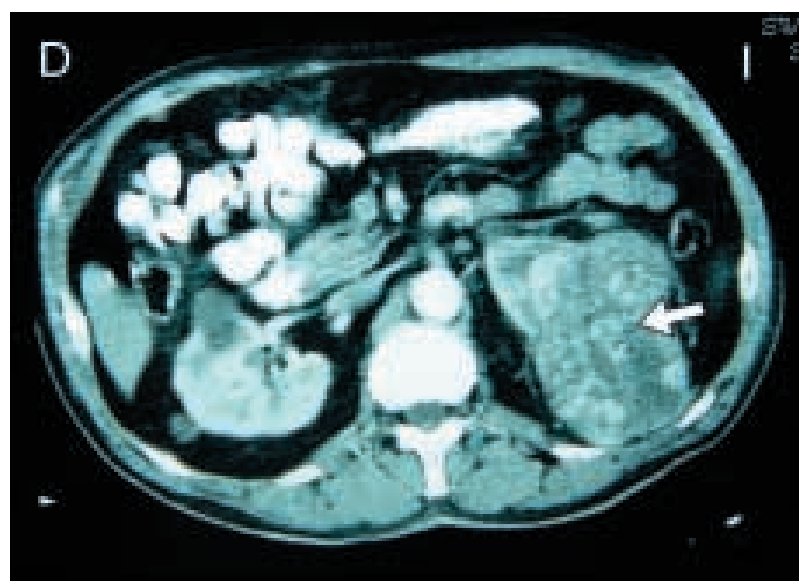

Fig. 9: Case 4. Abdominal CAT image. We observed a heterodense mass (arrow) on the upper pole of the left kidney plus necrotic areas.

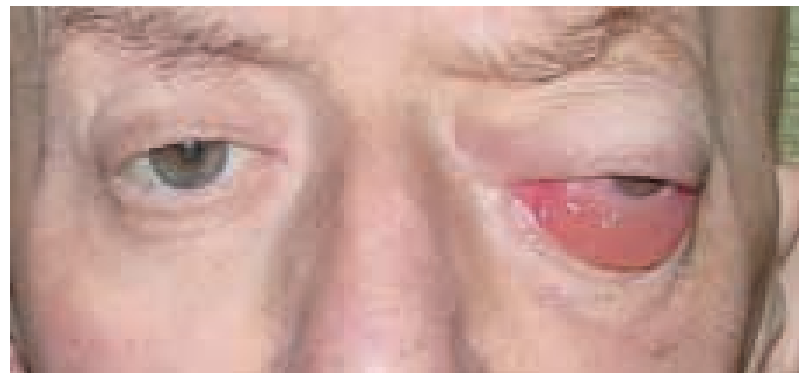

Fig. 10: Cas4 4. The patient exhibits exophthalmos, ptosis and obvious conjunctival chemosis.

tor's office complaining of 15-days-old hematuria. Through a CAT we observed a tumor on the left kidney (fig. 9). In July that same year, a left nephrectomy was performed, revealing that the tumor was a carcinoma of the renal cells. In February 2004, he was treated in the emergency ward due to epistaxis of the left nasal cavity. In April 2004 he was hospitalized due to an exophthalmos on the LE which had deteriorated in the last two weeks. Visual acuity of the LE is reduced to perception of hand movement at $50 \mathrm{~cm}$, glaucoma papillary excavation, palpebral ptosis and conjunctival chemosis (fig. 10). A CAT study revealed a mass on the left ethmoid extending to the sphenoid sinus and invading the orbit, anterior cranial cavity and cavernous sinuses, specially the left one (fig. 11).

In April 2004 we performed a biopsy of the lesion on the left middle meatus whose diagnosis is a renal cells adenocarcinoma (carcinoma of clear cells), which is considered as a metastasis of the renal neoplasia diagnosed two years earlier. In June

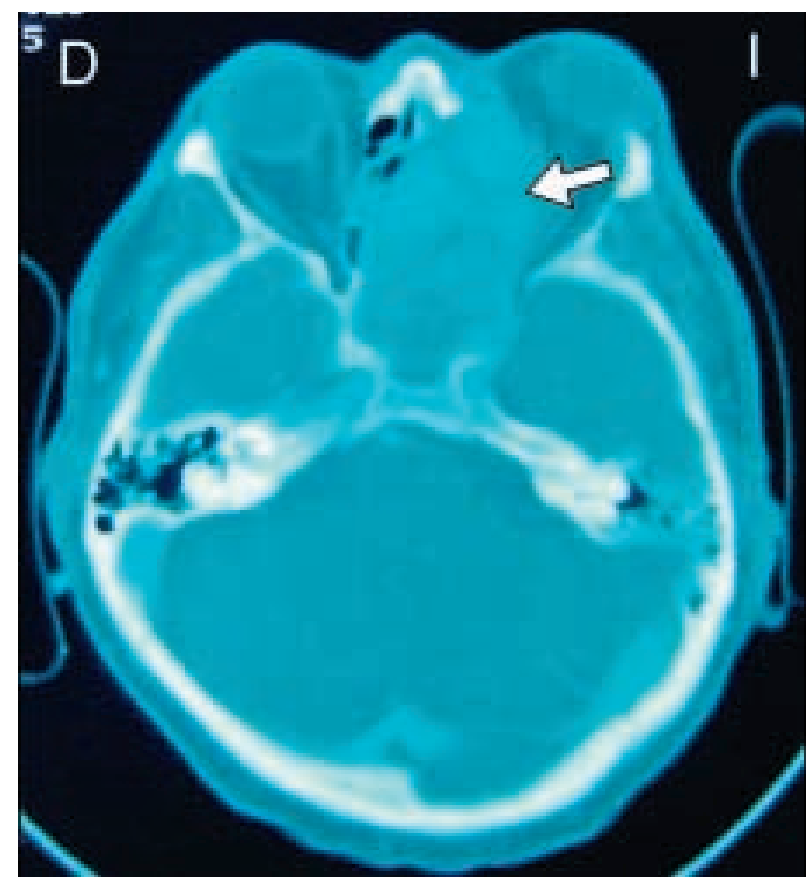

Fig. 11: Case 4. Cranial CAT. Observe the mass invading the left orbit.

2004 we began treatment with radiotherapy, chemotherapy and interleukin 2. In successive image controls, the condition remained stable, although the last CAT performed in August 2005 revealed a slight increase of the orbital-ethmoid mass. One year later, the patient remained in stable condition.

\section{DISCUSSION}

A study on 1,264 patients with orbital tumors (1) reported that metastases represented $7 \%$ of all cases. In a series of 244 patients, metastases amounted to $2 \%$ of all orbital tumors (9). Another study of 612 orbital studies with hystopathologic study with biopsy revealed that $6 \%$ were metastases (8). In our series, during the time period including the patients described herein (4 years) we registered 51 orbital tumors, four of which (approximately $8 \%$ ) corresponded to metastasis, thus coinciding with results obtained in other studies. Nonetheless, it is likely that the real numbers are greater, since we do not know for sure how many cancer patients may have developed undetected clinically silent orbital metastases (10).

Orbital metastases are less frequent than ocular ones $(11,12)$; they apparently show no preference 
for either orbit, and are rarely bilateral $(8,13)$, although in certain cases of primary mammary gland tumor it can appear simultaneously in both orbits (14). Its location on the orbit varies, although it appears more frequently in lateral (39\%) and upper (32\%) areas than in medial (20\%) and lower (12\%) areas (13). In our cases, the most frequent location was the medial area, as observed in a mammary metastasis and in lung and kidney metastases. In the second case of mammary metastasis it invaded almost the entire orbit. Different studies show a certain preference for a particular type of tissue. For instance, prostate metastases tend to be located in the bone; mammary metastasis in the fatty tissue and muscles; and melanomas in the muscle (12, 13). In our cases, mammary metastasis in the first case was possibly originated in the internal rectum of the right orbit, subsequently extending to the adjacent fatty tissue. In the second case of mammary metastasis it was impossible to determine which tissue was primarily affected, since by the time that image studies were performed it already had invaded almost all fatty tissue on the medial area of the orbit during the first study, and the second study showed its presence on all the orbital fat and had affected the muscle as well.

The most common cause of orbital metastasis is the mammary gland, lungs and prostate, except between $11 \%$ and $19 \%$ of cases $(8,13)$. A recent review points that the mammary gland represents $48 \%$ of primary tumor cases, followed by prostate and melanoma with $12 \%$, lungs with $8 \%$ and kidneys with $7 \%$ (1). In yet another series of 21 cases with orbital metastasis, we observe that the latter originated in the mammary gland in $67 \%$ of cases and in skin melanoma in $14 \%$ of cases (15). In another study of 20 cases, the origin was the mammary gland in $40 \%$ of cases, prostate in $10 \%$ and lung in $10 \%$ (16). A bibliographical review published in 1990 shows results obtained for the origin of metastases: $42 \%$ originated in the mammary gland, $11 \%$ in lungs, $8,3 \%$ in the prostate, $5.2 \%$ are melanomas and $3.2 \%$ in kidneys.

The frequency of orbital metastasis may be much greater than what is presented in published studies. When performing anatomopathological studies on patients suffering from mammary carcinoma, 10 to $37 \%$ show ocular or orbital metastases which had not been previously detected through clinical tests $(17,18-20)$. A recent study (10) points out that a center treating approximately 300 patients for mammary carcinoma with metastasis, only diagnosed 2 cases of orbital metastasis in the course of 5 years. This suggests that most orbital metastases accompanying mammary gland carcinoma are never diagnosed. Our cases involved three females and one male. In two females not previously diagnosed with primary tumors, we suspected the origin of metastasis to be a mammary gland tumor, confirming our suspicions in one of them. Although it is advisable to suspect the existence of a mammary carcinoma in any women presenting orbital mass, we should take into consideration the fact that orbital metastases in mammary tumors have also been described for males (10).

Orbital metastases have been reported to originate in many types of tumors located in different spots such as testicles, gallbladder and biliary duct, heart, mammary gland in males, skin, stomach, pleura, fatty tissues, thymus and bones (12). Asides from these spots, orbital metastasis has also been found in the bladder $(16,21)$, intestinal tract and throat $(16,22,23)$, malignant solitary fibrous tumor in tho$\operatorname{rax}(24)$, neuroendocrine tumor (25), dermatofibrosarcoma (26), renal medullar carcinoma (27), pleural mesothelioma (28), perineal alveolar rhabdomyosarcoma (29), pelvic teleangietatic osteosarcoma (30), spermatic cord leiomyosarcoma (31), ganglioneuroblastoma of the adrenal (32), forearm synovial sarcoma (33), pancreatic islets (34), hepatocellular liver carcinoma (35) and cervix (36) among others. In our 4-case series, location of the primary tumor matches the most frequently reported originating spots. Two were metastasis of mammary gland primary tumors, one lung and one kidney.

Unlike adults, children that suffer neoplasias generating orbital metastasis are usually not carcinomas but sarcomas, affecting the orbit rather than the eye globe (11). In our target population, neuroblastomas $(1,37)$ and Ewing sarcomas are more frequently metastasic to the orbit (1), although we find metastasis coming from other tumors (32).

We confirmed that in $60 \%$ of cases there is a history of primary tumor, especially in mammary gland tumors (38); in $30 \%$ of cases even a complete medical history of the patient does not reveal the existence of a primary tumor (12). We should consider that metastases may simulate other non-malignant injuries such as hemangiomas, myositis, thyroid orbitopathy and other inflammatory processes. Between 50 and $35 \%$ of patients visit the ophthalmologist unaware of the primary tumor that origi- 
nated their metastasis $(2,8,13)$. In our 4-case series, two already knew of the existence of a primary tumor, one in the mammary gland and another in the kidney, whereas in the remaining two cases, a mammary metastasis and a lung metastasis, primary tumors were found only after performing the study prescribed by the ophthalmologist.

Extensive review of publications concerning to orbital metastases (13) revealed that, in order of frequency, symptoms produced by orbital metastases are diplopia, pain and reduction of vision. Similarly, and in order of frequency, signals are proptosis, alterations of eye motility, emergence of a tangible mass, palpebral ptosis, displacement of the globe, conjunctival chemosis, enophthalmos, papilledema, retinal folds, paresthesias and pulsation. Unlike other primary expansive orbital processes, metastases tend to grow rapidly, symptoms appearing prematurely and in most cases are unilateral.

Alteration of ocular motility and proptosis are the earliest and most frequent symptoms associated with metastasis. Some studies reveal that restricted ocular motility appears in approximately $50 \%$ of cases (12). In a study covering 31 cases, $48 \%$ showed diplopia and $26 \%$ proptosis (8). Nevertheless, enophthalmos is not infrequent and appears in $10 \%$ of cases (11), particularly in scirrhous mammary tumors which tend to cause retraction and fibrosis on orbital tissues. All cases showed a marked alteration of ocular movement, including palpebral ptosis and proptosis, although substantially lower than the one present in mammary metastases (figures 2 and 3 ).

Pain tends to appear even earlier in expansive primary orbital processes. On occasion, affectation of the trigeminal nerve may be accompanied by hypoesthesia or paresthesias. Certain series indicate that this symptom appears in approximately $20 \%$ of cases $(12,13)$. In our series, pain was a relevant symptom only in cases of lung metastasis, which corresponded to the case where inflammation was greater (fig. 6).

Ocular pulsation, coincident with cardiac rythm, reveals osteolysis of the orbital roof, allows for transmission of cerebral pulsation. Only in certain cases where tumor metastases are highly vascularized, such as thiroid or renal tumors, pulsation may be due to the metastasis's own blood flow. This symptom is not frequent, as shown by a bibliographical review of orbital metastases where pulsation was only reported in $1.5 \%$ of cases (13).
Reduction of vision in the affected eye appeared in $20 \%$ of cases with orbital metastasis (13). We found this symptom in all cases, although in case 4 we could not assert that the loss of vision was a consequence of metastasis alone, since the patient had suffered severe trauma on that same eye.

Clinical conditions caused by orbital metastasis have been classified into five types according to their presentation (13). The mass symptom appears in $66 \%$ of cases and is characterized by displacement of the globe. The second type is known as infiltrative, and it appears in $24 \%$ of cases and is characterized by the presence of enophthalmos and restriction of ocular movement. It is particularly frequent in scirrhous mammary carcinoma metastases. The third type is inflammatory, and appears in $5 \%$ of cases. The fourth type is functional, it appears in 5\% of cases and normally takes place when metastasis settles in the orbit, usually the apex where, though taking up very little space, it causes significant functional alterations. Finally, the silent type characteristically is not accompanied by any symptoms and its finding is generally casual. These symptoms may appear in a concurrent manner. In our cases, the infiltrative symptom with very moderate exophthalmos appeared in two cases of mammary metastasis (figures 2 and 3). As shown in case 2 , despite the fact that the tumor invades almost the whole orbit (fig. 4), the resulting exophthalmos is much smaller than expected (fig. 3). The two remaining cases were characterized by a significant inflammation with marked ocular proptosis (figures 6 and 10). Both cases corresponded with lung and kidney metastases.

Often, patients with orbital metastasis tend to report the existence of an old or recent neo-formative process which will aid in diagnosis. In our series, two cases had a history of primary tumors (cases 2 and 4), and in another one (case 1) we performed a simple clinical exam and immediately found the primary tumor on the right mammary gland (fig. 2), whereas in case 3 we needed to undertake an extensive exam to detect the original tumor on the left lung.

Both CATs and NMRs are essential and most useful than ultrasound to assess orbits suspected of metastasic injuries $(12,39,40)$. CAT was chosen (11) since it allows for detecting bone affectations more accurately than NMR. Case 4 in our series illustrates how CATs are capable of revealing bone destruction of the left orbit's medial wall (fig. 11), 
while in the remaining cases osseous walls seem untouched.

The way in which orbital metastases manifest themselves through CAT and NMR images varies. CATs frequently identify a mass (58\%), followed by osseous alterations (25\%), muscular $(9 \%)$ and diffuse alteration (8\%) (11). As mentioned above, the appearance of a mass accompanied by muscular or fatty affectation generally suggests the presence of a mammary carcinoma metastasis, osseous affectation indicates the existence of prostate cancer and prevailing muscular affectation reveals a melanoma. Prostate cancer tends to cause hyperostosis, whereas thiroid cancer usually results in osteolysis. Approximately 50\% of metastases impact the bone; subsequently, if the bone lesion is not close to the lacrimal fossa or adjacent to periorbital sinuses it may indicate the presence of a metastasis (12). Nevertheless, we must take into consideration the fact that other lesions such as mucoceles (41), infection, Wegener's granulomatosis, malignant granuloma of the medial line, histiocytosis, sarcomas and lymphoid lesions may yield similar images to those generated by metastasis. In order to give a differential diagnosis, it's been suggested that if the NMR's T2 series shows hypointense signals it may correspond to an inflammatory pseudotumor, while hyperintense symptoms may reveal a lymphoma or metastasis (11). Most of the time, orbital metastases are located exclusively in extraconal spaces $(50 \%)$ and the rest are found either in intraconal spaces $(30 \%)$ or in both $(20 \%)(12)$. In our series, three cases (cases 1, 3 and 4) show a tumoral mass in the medial area of the orbit. In one of the cases (case 4) it probably reached the orbit by growing from the ethmoid or the sphenoid bones (fig. 11). In case 2, the tumoral mass invades almost the whole orbit, including the intraconal space. Unfortunately, despite our efforts to find a correlation between the image of the lesion and its anatomopathological study, the truth is that it is impossible to categorically assert the existence of a link. A survey of 31 cases of orbital metastasis, $26 \%$ were not detected with either CAT nor NMR, whereas in the remaining $74 \%$ the likelihood of a metastasis as probable cause rarely arised (8).

Ultrasounds proved to be less effective than CATs or RMNs when detecting the presence of orbital lesions caused by tumors. They are more useful in lesions located in front than in the back, and are particularly suited for cystic lesions. Com- bined with Dopplers, they may yield information regarding the tumor's vascularization (11).

Fine-needle Puncture and Aspiration Biopsy (FPAB) is an excellent choice in case one suspects the presence of metastasis. If successful, it allows to quickly provide anatomopathological diagnosis, helping locate the primary tumor and sparing patients a large number of explorations. This technique aids in obtaining material from tumors with abundant cellularity, whereas it proves barely effective in fibrous tumors (42). Prior to performing FPABs, we undertake an image study. Results obtained using this technique have been deemed excellent by some experienced authors (12) and several published series report 80 to $97 \%$ matches with subsequent anatomopathological diagnoses (8,43-45). The main concern regarding the use of FPAB is the possibility of disseminating tumoral cells, though studies performed on a large number of cases where FPABs were undertaken for a considerable range of tumors and locations show that, in this respect, the technique is safe (12). Although serious complications have been reported for FPABs, such as globe injury or brain lesions $(43,46)$, the probability of such complications taking place is extremely small $(45,47)$. FPABs may be avoided if, whatever the reason, the tumor is to be removed. In this case, the removed sample is used to obtain the anatomopathological diagnosis. In our series, we undertook FPABs of the orbital metastasis in cases 2 and 3, both of them positive. In the first case, the discovery of the mammary gland lesion (fig. 2) and reaction to treatment gave away the diagnosis. In the second case, a history of a long-lived renal tumor and a nasal biopsy rendered the FPAB unnecessary. Direct biopsy on the tumor by means of surgical intervention should only be undertaken if all other studies prove unable to provide a diagnosis, the possibility of metastasis and if the exact location of the primary tumor is unknown. In our series, only in one case did we perform direct biopsy on the metastasis.

Complementary data rarely help in diagnosing metastasis except when the primary tumor shows specific markers. High levels of carcinoembryonic antigens in the plasma reveal the existence of metastasis, although a negative result may not reveal its absence (38). In prostate cancer, alkaline phosphatase is high and seminomas produce human chorionic gonadotropin. In carcinoid syndromes, 5- 
indole acetic acid tends to be high in urine. In any event, determining the existence of a primary tumor is not the ophthalmologist's task and it is advisable to refer the patient to an oncology service for diagnosis and treatment.

Generally, patients with orbital metastasis are not good candidates for orbital surgery to remove the tumoral mass, since this will not cure the disease $(11,13)$. Nevertheless, in certain cases where the tumor grows slowly, removing the metastasis together with the primary tumor may improve the patient's prognosis (13). Whenever the orbital tumor leads to pain or loss of vision, palliative treatments may be undertaken in the form of radiotherapy, chemotherapy or even surgery. Radiotherapy treatment in these cases ranges from 3,000 to 4,000 rad (20 to $40 \mathrm{~Gy}$ ) distributed in several doses throughout one or two weeks, so that remittal improves the symptoms, including in some instances recovery of vision (11). Hormonal therapy has also been used as palliative treatment in metastases associated to hormone-sensitive cancers, such as prostate and breast cancer.

Prognosis for patients with orbital metastasis is bad in most cases and depends on the type and location of the primary tumor. Out of 245 cases of orbital metastasis published in medical literature, mean rate of survival since metastasis was detected amounted to 9.3 months (12). In a study of 30 cases, the distribution of survival averaged 1.3 years and $27 \%$ of cases survived for 2 years (8). The same study could not establish a link between survival and the knowledge of a primary tumor at the time when the orbital metastasis was detected. A series of 31 cases of orbital metastasis could not establish a link between its appearance on the CAT and NMR and subsequent prognosis (8). In our series, two patients have died due to the process caused by the orbital metastasis. Lung metastasis proved to be the most aggressive of all, the patient dying two months after visiting the ophthalmologist.

The possibility of an orbital metastasis needs to be taken into account in any orbital process. Frequently, ophthalmologists are the first physicians to see a patient with an orbital process caused by metastasis. A differential diagnosis is provided in cases where there is an orbital process combined with a predominant inflammatory component which may simulate cellulitis, arteriovenous fistula, myositis, endophthalmitis, thyroid orbitopathy or inflammatory pseudotumor. We need to keep in mind that in some patients a swollen orbit may be the first sign of a tumor located in another spot.

\section{REFERENCES}

1. Shields JA, Shields CL, Scartozzi R. Survey of 1264 patients with orbital tumors and simulating lesions.The 2002 Montgomery Lecture, part 1. Ophthalmology 2004; 111: 997-1008.

2. Font RL, Ferry AP. Carcinoma metastatic to the eye and orbit III. A clinicopathologic study of 28 cases metastatic to the orbit. Cancer 1976; 38: 1326-1335.

3. Fratkin JD, Purcell JJ, Krachmer JH, Taylor JC. Wilms' tumor metastatic to the orbit. JAMA 1977; 238: 18411842.

4. Clark WC. Adrenal neuroblastoma, with a particular reference to metastasis to the orbit: report of a case and notes on two other cases. Arch Ophthalmol 1939; 22: 575-580.

5. Kindermann WR, Shields JA, Eifeman RA, Stephens RF, Hirsch SE. Metastatic renal cell carcinoma to the eye and adnexae: a report of three cases and a review of the literature. Ophthalmology 1981; 88: 1347-1350.

6. Ferry AP, Naghdi MR. Bronchogenic carcinoma metastatic to the orbit. Arch Ophthalmol 1967; 77: 214-216.

7. Albert DM, Rubenstein RA, Scheie HG. Tumor metastasis to the eye. II. Clinical study in infants and children. Am J Ophthalmol 1967; 63: 727-732.

8. Char DH, Miller T, Kroll S. Orbital metastases: diagnosis and course. Br J Ophthalmol 1997; 81: 386-390.

9. Ohtsuka K, Hashimoto M, Suzuki Y. A review of 244 orbital tumors in Japanese patients during a 21 year period: origins and locations. Jpn J Ophthalmol 2005; 49: 49-55.

10. Dieing A, Schulz CO, Schmid P, Roever AC, LehenbauerDehm S, Jehn C, et al. Orbital metastases in breast cancer: report of two cases and review of the literature. $J$ Cancer Res Clin Oncol 2004; 130: 745-748.

11. Rootman J. Diseases of the orbit. II ed. Baltimore: Lippincot Williams \& Wilkins; 2003; 330-343.

12. Char DH. American Cancer Society. Atlas of Clinical Oncology. Tumors of the eye and ocular adnexa. Londres: BC Decker Inc; 2001: 413-420.

13. Goldberg RA, Rootman J, Cline RA. Tumors metastatic to the orbit: a changing picture. Surv Ophthalmol 1990; 35: $1-24$.

14. Tijl J, Koornneef I, Eijpe A, Thomas L, Gonzalez DG, Veenhof C. Metastatic tumors to the orbit-management and prognosis. Graefes Arch Clin Exp Ophthalmol 1992; 230: $527-530$.

15. Fahmy P, Heegaard S, Jensen OA, Prause JU. Metastases in the ophthalmic region in Denmark 1969-98. A histopathological study. Acta Ophthalmol Scand 2003, 81: 47-50.

16. Holland D, Maune S, Kovacs G, Behrendt S. Metastatic tumors of the orbit: a retrospective study. Orbit 2003; 22: 15-24.

17. Albert DM, Rubenstein RA, Scheie HG. Tumor metastasis to the eye. I. Incidence in 213 adult patients with generalized malignancy. Am J Ophthalmol 1967; 63: 723-726. 
18. Ferry AP, Font RL. Carcinoma metastatic to the eye and orbit. I. A clinicopathologic study of 227 cases. Arch Ophthalmol 1974; 92: 276-286.

19. Guether H, Jaenisch W, Rossbach K. On the incidence of ocular metastases. Munch Med Wochenschr 1965; 107: 939-941.

20. Merrill CF, Kauffman DI, Dimitrov NV. Breast cancer metastatic to the eye is a common entity. Cancer 1991; 68: 623-627.

21. Fynn-Thompson N, McKiernan JM, Fay A. Transitional cell carcinoma of the urinary bladder metastatic to the orbit. Opthal Plast Reconstr Surg 2003; 19: 165-167.

22. Takemoto $Y$, Nishida $N$, Kojiro S, Jimi A, Kojiro $M$. Metastatic carcinoid tumor in the orbit. Kurume Med J 2003; 50: 165-167.

23. Borota OC, Kloster R, Lindal S. Carcinoid tumour metastatic to the orbit with infiltration to the extraocular orbital muscle. APMIS 2005; 113: 135-139.

24. Glazer-Hockstein C, Syed NA, Warhol M, Gausas RE. Malignant solitary fibrous tumor metastatic to the orbit. Ophthal Plast Reconstr Surg 2004; 20: 471-473.

25. Sivagnanavel V, Riordan-Eva P, Jarosz J, Portmann B, Buxton-Thomas M. Bilateral orbital metastases from a neuroendocrine tumor. J Neuroophthalmol 2004; 24: 240-242.

26. Nakra T, Cook T, Douglas RS, Goldberg RA. Deramtofibrosarcoma protuberans metastatic to the orbit. Arch Ophthalmol 2004; 122: 1240-1241.

27. Zdinak LA, Nik NA, Hidayat AA, Hargett NA. Renal medullary carcinoma metastatic to the orbit: a clinicopathologic report. Ophthal Plast Reconstr Surg 2004; 20: 322-325.

28. Gibson A, Musa F, Pearson A, Wiggins J. Metastatic mesothelioma presenting with proptosis. Am J Ophthalmol 2004: 137: 968-969.

29. McCarthy ML, Wilson MW, Ibrahim F, Fuller CE, Kun LE, Haik BG. Primary perineal alveolar rhabdomyosarcoma metastatic to an extraocular muscle. Ophthal Plast Reconstr Surg 2003; 19: 333-335.

30. Mohadjer Y, Wilson MW, Fuller CE, Haik BG. Primary pelvic teleangiectatic osteosarcoma metastatic to both orbits. Ophthal Plast Reconstr Surg 2004; 20: 77-79.

31. Bakri SJ, Krohel GB, Peters GB, Farber MG. Spermatic cord leiomyosarcoma metastatic to the orbit. Am J Ophthalmol 2003; 136: 213-215.

32. Johnson TE, Toledano SR. Ganglioneuroblastoma metastatic to the orbit. Ophthal Plast Reconstr Surg 2003; 19: 330-333.
33. Buono LM, Silberschmidt A, Foroozan R, Savino PJ. Metastatic synovial sarcoma to the skull base and orbit. Am J Ophthalmol 2002; 134: 785-787.

34. Gotwald TF, Zinreich SJ, Schocke M, Frede T, Bellmann $R$, Nedden D. CT and MR imaging of orbital metastasis from islet cell carcinoma fo the pancreas. Am J Roentgenol 2000; 175: 475-476.

35. Gupta R, Honavar SG, Vemuganti GK. Orbital metastasis from hepatocellular carcinoma. Surv Ophthalmol 2005, 50: 485-489.

36. Lee HM, Choo CT, Poh WT. Orbital metastasis from carcinoma of cervix. Br J Ophthalmol 1997; 81: 330-331.

37. Musarella MA, Chan HS, De Boer G, Gallie BL. Ocular involvement in neuroblastoma: prognostic implications. Ophthalmology 1984; 91: 936-940.

38. Bullock JD, Yanes B. Ophthalmic manifestations of metastatic breast cancer. Ophthalmology 1980; 87: 961-973.

39. Char DH, Sobel D, Kelly WM, Kjos BO, Norman D. Magnetic resonance scanning in orbital tumor diagnosis. Ophthalmology 1985; 92: 1305-1310.

40. DiBernardo C, Pacheco EM, Hughes FR, Iliff WJ, Byrne $S F$. Echographic evaluation and findings in metastatic melanoma to extraocular muscles. Ophthalmology 1996; 103: 1794-1797.

41. Gonzalez F, Garcia A, Prieto A. Mucocele frontoetmoidal con afectación ocular. Arch Soc Esp Oftalmol 2005; 80. 301-303.

42. Kennerdell JS, Slamovits TL, Dekker A, Johnson BL. Orbital fine-needle aspiration biopsy. Am J Ophthalmol 1985; 99: 547-551.

43. Zeppa P, Tranfa F, Errico ME, Troncone G, Fulciniti F, Vetrani A, et al. Fine-needle aspiration (FNA) biopsy of orbital masses: a critical review of 51 cases. Cytopathology 1997; 8: 366-372.

44. Gupta S, Sood B, Gulati M, Takhtani D, Bapuraj R, Khandelwal $N$, et al. Orbital mass lesions: US-guided fineneedle aspiration biopsy - experience in 37 patients. Radiology 1999; 213: 568-572.

45. Arora R, Rewari R, Betharia SM. Fine needle aspiration cytology of orbital and adnexal masses. Acta Cytol 1992; 36: 483-491.

46. Karcioglu ZA, Gordon RA, Karcioglu GL. Tumor seeding in ocular fine-needle aspiration biopsy. Ophthalmology 1985; 92: 1763-1767.

47. Liu D. Complications of fine needle aspiration biopsy of the orbit. Ophthalmology 1985; 92:1768-1771. 